\title{
Aclimatização de plantas micropropagadas de videira cv. Bordô (Vitis labrusca L.) em diferentes substratos
}

\section{Acclimatization of micropropagated plants of fox grape cv. Bordô (Vitis labrusca L.) in different substrates}

\author{
Mariane Ruzza Schuck ${ }^{1 *}$, Bernardo Lipski², André Luís Lopes da Silva ${ }^{3 *}$, Dayse Cristina \\ de Carvalho² e Luiz Antonio Biasi² \\ ${ }^{1}$ Laboratório de Bioquímica, Biotecnologia e Bioprodutos, Instituto de Ciências da Saúde, Universidade Federal da \\ Bahia, 40160-100, Salvador, BA - Brasil. ${ }^{2}$ Laboratório de Micropropagação de Plantas, Departamento de \\ Fitotecnia e Fitossanitarismo da Universidade Federal do Paraná (UFPR), Curitiba, PR - Brasil. ${ }^{3}$ Divisão de \\ Engenharia de Bioprocessos e Biotecnologia; UFPR; 81531-970; Curitiba - PR - Brasil.
}

\begin{abstract}
The substrate must promote the growth of the plants, being an important component during the acclimatization of micropropagated plants. The aim of this research was to evaluate the effects of different substrates during the acclimatization of fox grape $c v$. Bordô. The experiment was carried out at the greenhouse during February and March of 2009. Five substrates were tested: Plantmax ${ }^{\circledR}$ HT, Plantmax ${ }^{\circledR}$ HT: Coconut fiber (7,5:2,5 v/v), Plantmax ${ }^{\circledR}$ HT: Coconut fiber $(1: 1 \mathrm{v} / \mathrm{v})$, Plantmax ${ }^{\circledR}$ HT: Coconut fiber $(2,5: 7,5 \mathrm{v} / \mathrm{v})$ and Coconut fiber. The process of acclimatization consisted of three phases. After 20 days of in vitro culture, it was removed the PVC film (Polyvinyl chloride) that covered the flasks and after two days, flasks had lids partial opening for two hours at the growth room conditions. The plants were transferred for the different substrates and placed in a greenhouse with intermittent nebulization during 16 days proceeded by 20 days of daily manual irrigation. The best substrate for acclimatization of fox grape $c v$. Bordô was Plantmax ${ }^{\circledR} H$, benefitting the formation of roots and aerial part of the plants. The coconut fiber must not be used alone as substrate or in larger proportions than $25 \%$ in the mixture with Plantmax ${ }^{\circledR} H T$.
\end{abstract}

Key-words: Coconut fiber, micropropagation, seedling production, plantmax, tissue culture

\section{INTRODUÇÃO}

No Brasil, uvas do cultivar Bordô (Vitis labrusca L.) são usadas para produção de vinho tinto, suco, vinagre e geléias. O plantio do cultivar Bordô tem crescido expressivamente nos últimos anos na região sul do Brasil. Devido à crescente demanda deste cultivar, a micropropagação é uma alternativa viável e eficiente para a obtenção em grande escala de plantas matrizes com ótima qualidade fitossanitária (Machado et al., 2011). Além disso, diferentes cultivares se comportam de forma diferente com relação à técnica de micropropagação, o que torna necessário a adaptação de protocolos para clones ou cultivares específicos (Carvalho et al., 2011).

A aclimatização é uma fase da micropropagação que pode ser crítica se não permitir elevada taxa de sobrevivência das plantas (Lopes da Silva et al., 2007). Na aclimatização, as plantas sofrem muitos estresses durante a transferência das condições in vitro para as condições ex vitro. O tipo de substrato, dependendo de suas características físico-químicas, entre elas sua capacidade de retenção de água, influencia na sobrevivência, crescimento e desenvolvimento das plântulas (Lopes da Silva et al., 2006). Uma das causas da baixa sobrevivência de plântulas na aclimatização deve-se a excessiva perda de água que estas sofrem durante o período de aclimatização (Sutter e Langhans, 1982).

Com base nessas considerações, um substrato com elevado espaço de aeração associado à elevada capacidade de retenção de água é desejado para a aclimatização de plantas micropropagadas. Porém,

Author for correspondence: clonageinvitro@yahoo.com.br 
substratos formados por um único material dificilmente irão suprir essas necessidades adequadamente. Por isto, geralmente utiliza-se mistura de substratos (Kämpf, 2000). A fibra de coco apresenta características interessantes e apresenta grande potencial para uso na composição de substratos. A fibra de coco apresenta alta capacidade de retenção de água, boa drenagem, acidez; e variação nos teores de nutrientes (Abad et al., 2002).

O Plantmax ${ }^{\circledR}$ HT é um substrato comercial que mistura diferentes materiais: casca de pinus, turfa, vermiculita expandida e carvão moído, oferecendo granulometria específica formada pela diferença de tamanho de partículas dos materiais envolvidos. Partículas com maior diâmetro são responsáveis pela formação de poros maiores (macroporos), que são ocupados pelo ar. Por outro lado, partículas de menor diâmetro são responsáveis pela formação de poros menores (microporos), que são ocupados por água (Zanetti et al., 2003). O Plantmax ${ }^{\circledR}$ HT é bastante utilizado para aclimatização de plantas micropropagadas, no entanto, é considerado de alto custo.

O objetivo deste trabalho foi avaliar o potencial da fibra de coco, isolada e em combinação com plantmax $^{\circledR}$ HT na aclimatização de plantas micropropagadas de videira cv. Bordô em casa-devegetação.

\section{MATERIAL E MÉTODOS \\ Estabelecimento $e$ multiplicação in vitro de plantas de videira cv. Bordô}

Estacas herbáceas de 'Bordô' (Vitis labrusca L.) oriundas do campo foram usadas como doadoras de segmentos nodais (3 $\mathrm{cm}$ de comprimento com uma gema e as folhas foram removidas). Esses explantes foram deixados por 30 minutos em água corrente e em seguida foram imersos em solução de etanol $70 \%$ adicionada com $2 \mathrm{~mL} . \mathrm{L}^{-1}$ de Tween ${ }^{\circledR}$ 20 por 20 segundos, seguida de imersão em solução de $\mathrm{NaOCl} 1 \%$ por 20 minutos, após os explantes foram enxaguados 4 vezes com água destilada e autoclavada. $\mathrm{O}$ meio de cultura foi o meio MS (Murashige e Skoog, 1962) com 30 g.L $\mathrm{L}^{-1}$ de sacarose e 6 g.L.$^{-1}$ de ágar $\left(\right.$ Vetec $\left.^{\circledR}\right)$ e o pH foi ajustado para 5,8 .

As plantas regeneradas pelo estabelecimento in vitro a partir dos segmentos nodais foram sucessivamente multiplicadas usando segmentos nodais como explantes, esses segmentos continham uma gema axilar, uma folha e tinham $1,0 \mathrm{~cm}$ de comprimento. As plantas obtidas no sexto subcultivo foram utilizadas para o experimento de aclimatização. $\mathrm{O}$ meio de multiplicação foi o mesmo usado para o estabelecimento in vitro. Foram inoculados cinco explantes por frasco coberto com tampa de polipropileno rígido, além disso, foi colocada uma camada de filme transparente de polivinilcloreto (PVC) para garantir que os frascos estivessem vedados. Os explantes permaneceram em sala de crescimento com fotoperíodo de 16 horas fornecida por lâmpadas fluorescentes do tipo "luz do dia", com intensidade luminosa de aproximadamente $20 \mu \mathrm{M} \cdot \mathrm{m}^{-2} \cdot \mathrm{s}^{-1}$ e temperatura de $25 \pm 2^{\circ} \mathrm{C}$.

\section{Pré-aclimatização e aclimatização em diferentes substratos}

Antes das plantas serem retiradas dos frascos foi realizada uma pré-aclimatização, a qual consistiu da remoção do filme de PVC dos frascos por 2 dias. Antes da abertura dos frascos, as tampas de polipropileno foram deixadas semi-abertas por 2 horas. Após esse período as plantas foram removidas do meio de cultura, as raízes foram lavadas com água de distruibuição urbana para retirada do meio de cultura. As plantas foram transplantadas nos diferentes substratos: (S1) Plantmax ${ }^{\circledR}$ HT, (S2) Plantmax ${ }^{\circledR}$ HT:fibra de coco (7,5:2,5 v/v), (S3) Plantmax ${ }^{\circledR}$ HT:fibra de Coco $(1: 1 \mathrm{v} / \mathrm{v}), \quad$ (S4) Plantmax ${ }^{\circledR}$ HT:fibra de coco $(2,5: 7,5 \mathrm{v} / \mathrm{v})$ e (S5) fibra de coco. Os substratos foram acondicionados em tubetes com $53 \mathrm{~cm}^{3} \mathrm{de}$ volume.

As plantas cultivadas nesses substratos foram cultivadas sob nebulização intermitente (15 segundos de nebulização a cada 30 minutos das 08:00 às 17:00 horas, 15 segundos de nebulização a cada 1 hora das 17:00 às 23:00 horas e 15 segundos de nebulização a cada 3 horas das 23:00 às 08:00 horas) em casa-de-vegetação por 16 dias, em seguida as plantas foram trasnferidas da nebulização e submetidas à rega manual diária por 20 dias. Foram avaliadas: altura da parte aérea (AP $\mathrm{cm}$ ), número de folhas $(\mathrm{NF})$, número de raízes primárias (NRP), comprimento total das raízes $(\mathrm{CR} \mathrm{cm})$, massa fresca (MFR g) e seca das raízes (MSR g), massa fresca (MFP g) e seca da parte aérea (MSP g), relação entre massa seca da parte área e massa seca das raízes (PA/R), taxa de sobrevivência $(\mathrm{S} \%)$, volume das raízes $\left(\mathrm{VR} \mathrm{cm}^{3}\right)$ e do pecíolo $\left.(\mathrm{VP} \mathrm{cm})^{3}\right)$ e a área foliar $\left(\mathrm{AF} \mathrm{cm}^{2}\right)$ aos 36 dias de cultivo ex vitro. Comprimento total de raízes, volume das raízes, volume do peciolo e 
area foliar foram obtidos com auxílio do equipamento WIN RHIZO MAC LA1600 produzido pela Instruments Régent. A massa seca foi determinada em estufa com ventilação de ar forçada a $65^{\circ} \mathrm{C}$ por $48 \mathrm{~h}$. Foi realizada a caracterização física dos substratos, tais como densidade (D g.L L $^{-1}$ ), espaço poroso total (EPT \%), retenção de água na capacidade de campo (ARCC $\%$ ) e espaço de ar na capacidade de campo (EACC $\%$ ), através de uma determinação rápida proposta por Fretz et al. (1979), as médias foram obtidas a partir de três repetições.

$\mathrm{O}$ delineamento experimental utilizado foi inteiramente casualisado. Foram utilizadas cinco repetições com cinco plantas. Os dados foram submetidos à análise de variância e ao teste de Duncan ao nível de 5\% de probabilidade de erro. Os dados tiveram a sua normalidade avaliada pelo teste de Lilliefors e os dados oriundos de contagem foram transformados para $\sqrt{x+0,5} \mathrm{e}$ os de percentagem para arcoseno $\sqrt{x / 100}$. Os dados foram processados com auxílio do programa computacional GENES (Cruz, 2001).

\section{RESULTADOS}

As variáveis, porcentagem de sobrevivência e número de raízes primárias não apresentaram significância estatística. A sobrevivência das mudas foi $100 \%$, com exceção do substrato composto por fibra de coco, que foi de $96 \%$. O número de raízes primárias variou de 3,4 a 4,9 (Tabela 1). O número de folhas não diferiu estatisticamente entre os substratos S1, S2, S3 e $\mathrm{S} 4$, entretanto o substrato $\mathrm{S} 5$ foi significativamente inferior aos demais (Tabela 2). Os substratos $\mathrm{S} 1 \mathrm{e}$ S3 apresentaram o volume do pecíolo maior que os demais substratos, entretanto não diferiram dos substratos S2 e S4, porém foram superiores ao substrato S5 (Tabela 2).

As variáveis, relação da massa seca da parte aérea pela massa seca das raízes (PA/R), massa fresca da parte aérea, área foliar e altura da parte aérea não apresentaram diferenças estatísticas entre os substratos S1 e S2, porém esses substratos foram superiores com os demais substratos para essas variáveis (Tabela 1 e 2). O substrato $\mathrm{S} 1$ apresentou os melhores resultados para as variáveis, massa seca da parte aérea, comprimento da maior raiz, massa fresca das raízes, massa seca das raízes e volume das raízes (Tabela 1 e 2).
As análises físicas dos substratos indicaram que a densidade e o espaço de ar na capacidade de campo dos substratos diminuem em função do aumento da proporção da fibra de coco. No entanto, com o aumento da proporção da fibra de coco no substrato, o espaço poroso total e a água retida na capacidade de campo aumentam (Tabela 3).

\section{DISCUSSÃO}

A pré-aclimatização realizada antes da remoção das mudas dos frascos pode ter influenciado para maior rustificação das mudas, de forma semelhante como observado em plantas micropropagadas de Eucalyptus saligna (Lopes da Silva et al., 2011), sendo benéfica para a sobrevivência das mudas.

As altas taxas de sobrevivência foram similares com as taxas obtidas por Biasi et al. (1998) em porta-enxerto de videira cv. Jales e por Borghezan et al. (2003) com os porta-enxertos VR043-43, VR039-16, Paulsen 1103, R110, SO4 e Kober $5 \mathrm{BB}$, sugerindo que o tipo de cultivar não difere com relação a sobrevivência durante a aclimatização. Por outro lado, Alizadeh et al., (2010) e Cutanda et al. (2008), obtiveram taxas bem menores com os porta-enxertos Dogridge, SO4, H-144 e 3309 C e os cultivares espanhóis 'Macabeo' e 'Tempranilho', respectivamente.

A aclimatização de videiras micropropagadas é considerada uma etapa crucial, uma vez que as plântulas apresentam conexões vasculares entre caule e raízes ainda deficientes, além de excessiva transpiração devido aos estômatos não funcionais e à precária camada de cera epicuticular. $\mathrm{O}$ grau de sucesso da fase de aclimatização, bem como de outras etapas da cultura de tecidos pode ser genótipo-dependente e pode variar de acordo com as condições de cultivo (Banilas e Korkas, 2007). O substrato Plantmax ${ }^{\circledR}$ também beneficiou a altura de mudas em porta-enxertos de citros, comparado a outros substratos com granulação fina e fibra de coco (Franco et al., 2007). O substrato Plantmax ${ }^{\circledR}$ HT exerceu influencia positiva no crescimento das mudas por ter aumentado a área foliar, favorecendo maior desempenho fotossintético que é importante para a sobrevivência das mudas no campo. Tal resultado possivelmente ocorreu em função da granulometria mais grossa oferecida pela presença do Plantmax ${ }^{\circledR}$ HT nesses substratos. 
Tabela 1. Sobrevivência das mudas ( $\mathrm{S} \%$ ), comprimento total das raízes ( $\mathrm{CR} \mathrm{cm}$ ), número de raízes primárias (NRP), volume das raízes (VR cm³), massa fresca das raízes (MFR g), massa seca das raízes (MSR g) e relação da massa seca da parte aérea com a massa seca das raízes (PA/R) aos 36 dias de cultivo ex vitro.

\begin{tabular}{lccccccc}
\hline Substratos $^{2}$ & S \% & CR cm & NRP & MFR g & MSR g & PA/R & VR $^{\mathbf{3}}$ \\
\hline S1 & $100 \mathrm{a}^{1}$ & $14,9 \mathrm{a}$ & $4,9 \mathrm{a}$ & $0,517 \mathrm{a}$ & $0,057 \mathrm{a}$ & $2,3 \mathrm{a}$ & $0,785 \mathrm{a}$ \\
S2 & $100 \mathrm{a}$ & $12,6 \mathrm{~b}$ & $3,6 \mathrm{a}$ & $0,309 \mathrm{~b}$ & $0,029 \mathrm{~b}$ & $1,9 \mathrm{ab}$ & $0,467 \mathrm{~b}$ \\
S3 & $100 \mathrm{a}$ & $12,4 \mathrm{~b}$ & $3,4 \mathrm{a}$ & $0,274 \mathrm{~b}$ & $0,027 \mathrm{~b}$ & $1,6 \mathrm{~b}$ & $0,454 \mathrm{~b}$ \\
S4 & $100 \mathrm{a}$ & $11,7 \mathrm{~b}$ & $3,6 \mathrm{a}$ & $0,235 \mathrm{~b}$ & $0,026 \mathrm{~b}$ & $1,5 \mathrm{~b}$ & $0,364 \mathrm{~b}$ \\
S5 & $96,0 \mathrm{a}$ & $11,3 \mathrm{~b}$ & $4,5 \mathrm{a}$ & $0,238 \mathrm{~b}$ & $0,024 \mathrm{~b}$ & $1,4 \mathrm{~b}$ & $0,357 \mathrm{~b}$ \\
\hline Média geral & 99,2 & 12,5 & 4,0 & 0,314 & 0,032 & 1,7 & 0,485 \\
\hline CV $(\%)$ & 5,9 & 10,2 & 9,3 & 26,3 & 23,5 & 26,7 & 22,5 \\
\hline
\end{tabular}

${ }^{\mathrm{T}}$ Médias seguidas por letras idênticas nas colunas não diferem entre si pelo teste de Duncan ao nível de 5\% de probabilidade de erro. ${ }^{2} \mathrm{~S} 1=$ Plantmax ${ }^{\circledR}$ HT, S2 $=$ Plantmax $^{\circledR}$ HT: fibra de Coco $(7,5: 2,5$ v/v $), S 3=$ Plantma ${ }^{\circledR}$ HT:fibra de Coco $(1: 1 \mathrm{v} / \mathrm{v}), \mathrm{S} 4=$ Plantmax ${ }^{\circledR}$ HT: fibra de Coco $(2,5: 7,5 \mathrm{v} / \mathrm{v})$ e S5 = fibra de Coco.

Tabela 2. Altura da parte aérea $(\mathrm{AP} \mathrm{cm})$, número de folhas $(\mathrm{NF})$, massa fresca da parte aérea (MFP $\mathrm{g}$ ), massa seca da parte aérea (MSP g), área foliar $\left(\mathrm{AF} \mathrm{cm}^{2}\right)$ e volume do pecíolo $(\mathrm{VP} \mathrm{cm})$ aos 36 dias de cultivo ex vitro.

\begin{tabular}{lcccccc}
\hline Substratos $^{2}$ & AP cm & NF & MFP g & MSP g & AF cm $^{2}$ & $\mathbf{V P ~ c m}^{\mathbf{3}}$ \\
\hline S1 & $5,7 \mathrm{a}$ & $4,1 \mathrm{a}$ & $0,406 \mathrm{a}$ & $0,071 \mathrm{a}$ & $29,7 \mathrm{a}$ & $0,116 \mathrm{a}$ \\
S2 & $5,2 \mathrm{ab}$ & $4,0 \mathrm{a}$ & $0,346 \mathrm{ab}$ & $0,052 \mathrm{~b}$ & $25,8 \mathrm{ab}$ & $0,097 \mathrm{ab}$ \\
S3 & $4,7 \mathrm{~b}$ & $4,0 \mathrm{a}$ & $0,305 \mathrm{bc}$ & $0,044 \mathrm{bc}$ & $21,6 \mathrm{bc}$ & $0,116 \mathrm{a}$ \\
S4 & $4,7 \mathrm{~b}$ & $3,8 \mathrm{a}$ & $0,252 \mathrm{~cd}$ & $0,042 \mathrm{bc}$ & $16,9 \mathrm{~cd}$ & $0,088 \mathrm{ab}$ \\
S5 & $4,4 \mathrm{~b}$ & $3,2 \mathrm{~b}$ & $0,194 \mathrm{~d}$ & $0,035 \mathrm{c}$ & $12,7 \mathrm{~d}$ & $0,069 \mathrm{~b}$ \\
\hline Média geral & 4,9 & 3,8 & 0,300 & 0,048 & 21,3 & 0,097 \\
\hline CV $(\%)$ & 10,5 & 4,3 & 22,0 & 23,3 & 21,7 & 28,6 \\
\hline
\end{tabular}

${ }^{1}$ Médias seguidas por letras idênticas nas colunas não diferem entre si pelo teste de Duncan ao nível de 5\% de probabilidade de erro. ${ }^{2} \mathrm{~S} 1=$ Plantmax $^{\circledR}$ HT, S2 $=$ Plantmax $^{\circledR}$ HT: fibra de Coco $(7,5: 2,5 \mathrm{v} / \mathrm{v}), \mathrm{S} 3=$ Plantmax $^{\circledR}$ HT:fibra de Coco (1:1 v/v), S4 = Plantmax ${ }^{\circledR}$ HT: fibra de Coco (2,5:7,5 v/v) e S5 = fibra de Coco.

A granulometria é uma característica importante para os substratos recomendados para a produção de mudas e deve favorecer a formação de espaços adequados de ar dentro dos recipientes de modo a permitir melhor desenvolvimento das raízes (Zanetti et al., 2003), consequentemente resultando em maior absorção de nutrientes. A vermiculita presente no substrato Plantmax ${ }^{\circledR}$ oferece maior aeração, necessária ao fornecimento de oxigênio para a respiração, proporcionando emissão mais rápida de raízes (Hoffmann et al., 2001). Além, de o plantmax ${ }^{\circledR}$ possuir maior quantidade de nutrientes do que a fibra de coco.
Villa et al. (2006) usando o substrato Plantmax ${ }^{\circledR} \mathrm{e}$ comparado com a vermiculita e casca de arroz carbonizada observou resultados semelhantes a esse presente estudo no que se refere ao bom desempenho do Plantmax $^{\circledR}$ para 0 desenvolvimento das raízes. As raízes são importantes para o bom desenvolvimento e fixação das mudas no campo e aparentemente as características físicas e químicas apresentadas por este substrato afetaram de forma positiva o desenvolvimento das raízes. 
Tabela 3. Análise física dos substratos. Densidade (D g.L $\left.\mathrm{L}^{-1}\right)$, espaço poroso total (EPT \%), água retida na capacidade de campo (ARCC \%) e espaço de ar na capacidade de campo (EACC \%).

\begin{tabular}{ccccc}
\hline Substratos $^{2}$ & D g. $^{\mathbf{1}}$ & EPT \% & ARCC \% & EACC \% \\
\hline S1 & $396,3^{1}$ & 66,6 & 47,7 & 18,9 \\
S2 & 347,3 & 70,3 & 57,7 & 12,6 \\
S3 & 252,9 & 76,4 & 65,6 & 10,8 \\
S4 & 185,8 & 86,4 & 76,9 & 9,5 \\
S5 & 125,5 & 89,0 & 82,9 & 6,1 \\
\hline
\end{tabular}

${ }^{1}$ Médias obtidas de três repetições. ${ }^{2} \mathrm{~S} 1=$ Plantmax $^{\circledR}$ HT, S2 $=$ Plantmax ${ }^{\circledR}$ HT: fibra de Coco $(7,5: 2,5 \mathrm{v} / \mathrm{v}), \mathrm{S} 3=$ Plantmax ${ }^{\circledR}$ HT:fibra de Coco $(1: 1 \mathrm{v} / \mathrm{v}), \mathrm{S} 4=$ Plantmax ${ }^{\circledR}$ HT: fibra de Coco $(2,5: 7,5 \mathrm{v} / \mathrm{v})$ e S5 = fibra de Coco.

Em geral, os tratamentos S1 (plantmax $\left.{ }^{\circledR}\right)$ e S2 (75\% plantmax ${ }^{\circledR}$ e $25 \%$ fibra de coco) favoreceram melhores resultados. Essa superioridade pode ser explicada pelas características físicas desses substratos (Tabela 3). Verificou-se que esses dois substratos apresentaram maior espaço de aeração (18,9\% e $12,6 \%$, respectivamente) e valores de densidade $\quad\left(396,3 \quad \mathrm{~g} \quad \mathrm{~L}^{-1}\right.$ e 347,3 g $\quad \mathrm{L}^{-1}$, respectivamente) considerados satisfatórios para propagação em tubetes $\left(250\right.$ a $\left.400 \mathrm{Kg} \mathrm{m}^{-3}\right)$ segundo Kämpf (2000). Consequentemente, os substratos que promoveram resultados inferiores para todas as variáveis analisadas neste trabalho (S3, S4 e S5) apresentaram, segundo a análise física (Tabela 3), resultados inferiores para densidade $\left(252,9 \mathrm{~g} \mathrm{~L}^{-1}, 185,8 \mathrm{~g} \mathrm{~L}^{-1} \mathrm{e} 125,5 \mathrm{~g} \mathrm{~L}^{-1}\right) \mathrm{e}$ espaço de aeração $(10,8 \% \quad 9,5 \%$ e $\quad 6,1 \%)$, respectivamente.

A densidade que o substrato apresenta fornece uma ideia prévia de características como porosidade e espaço de aeração. Boa aeração é uma das características físicas importantes para o crescimento de plantas em recipientes (Beardsell et al., 1979). Não somente a água é necessária para as plantas, mas também o ar é importante para o crescimento radicial (Verdonck et al., 1981). Sendo assim, verifica-se a importância da escolha correta do substrato a ser utilizado. Um bom substrato para a produção de mudas frutíferas deve proporcionar retenção de água suficiente e, quando saturado (em excesso de água), deve manter quantidades adequadas de espaço poroso para facilitar o fornecimento de oxigênio, indispensável no processo de propagação (Smiderle e Minami, 2001).

Segundo Hoffmann et al. (2001), o plantmax ${ }^{\circledR}$ apresenta vantagem pela sua uniformidade de composição química e física, diferentemente do que pode ocorrer com o solo e distintos materiais orgânicos, os quais podem variar muito nas suas características. Embora o tratamento S5 (fibra de coco) tenha apresentado valores de porosidade total (89\%) e capacidade de retenção de água $(82,9 \%)$ (Tabela 3), próximos à faixa considerada ideal por Kämpf (2000), neste trabalho, a fibra de coco não se mostrou eficiente como substrato na aclimatização de videira cv. Bordô. Foi observado que à medida que se aumentou a proporção de fibra de coco em relação ao plantmax ${ }^{\circledR}$ menores foram os valores do comprimento total das raízes, massa fresca e seca das raízes e da parte aérea, e área foliar, concordando com os resultados obtidos por Costa et al. (2007). Tal fato pode ser atribuído a uma possível limitação de nutrientes neste resíduo, conforme também observado por Rosa et al. (2001). Tais resultados sugerem que a fibra de coco poderia ser usada de forma eficiente, caso fosse suplementada com nutrientes.

\section{CONCLUSÃO}

O melhor substrato para aclimatização de videira cv. Bordô foi o Plantmax $^{\circledR}$, beneficiando a formação de raízes e parte aérea das mudas. A fibra de coco não deve ser utilizada sozinha como substrato ou em proporções maiores do que $25 \%$ na mistura com o Plantmax ${ }^{\circledR}$.

\section{RESUMO}

O substrato deve favorecer o crescimento das plantas, sendo um componente importante durante a aclimatização de plantas micropropagadas. O objetivo desse trabalho foi avaliar o efeito de diferentes substratos durante a aclimatização de videira cv. Bordô. $\mathrm{O}$ experimento foi conduzido em casa de vegetação durante os meses de fevereiro a março de 2009. Foram testados cinco substratos: Plantmax ${ }^{\circledR}$ HT, Plantmax ${ }^{\circledR}$ 
HT: fibra de Coco (7,5:2,5 v/v), Plantmax ${ }^{\circledR}$ HT:fibra de Coco (1:1 v/v), Plantmax ${ }^{\circledR}$ HT: fibra de Coco $(2,5: 7,5$ v/v) e fibra de Coco. O processo de aclimatização consistiu de três fases. Após cultivo in vitro por 20 dias, foi retirado o plástico de PVC (polivinilcloreto) que cobria os frascos e após dois dias houve abertura parcial das tampas de polipropileno por duas horas em sala de crescimento. As plantas foram transferidas para tubetes contento os diferentes substratos e colocadas em casade-vegetação, com nebulização intermitente durante 16 dias seguidos por 20 dias de rega manual diária. O melhor substrato para aclimatização de videira cv. Bordô foi o Plantmax ${ }^{\circledR}$ HT, beneficiando a formação de raízes e parte aérea das mudas. A fibra de coco não deve ser utilizada sozinha como substrato ou em proporções maiores do que $25 \%$ na mistura com o Plantmax ${ }^{\circledR}$ HT.

Palavras-chave: Fibra de coco, micropropagação, produção de mudas, plantmax, cultura de tecidos

\section{REFERÊNCIAS}

Abad, M.; Noguera, P.; Puchades, R.; Maquierira, A.; Noguera, V. (2002), Physico-chemical and chemical properties of some coconut coir dusts for use as peat substitute for containerized ornamental plants. Bioresource Technology, 82, 241-245.

Alizadeh, M.; Singh, S. K.; Patel, V. B. (2010), Comparative performance of in vitro multiplication in four grapes (Vitis spp.) rootstock genotypes. International Journal of Plant Production, 4, 41-50.

Banilas, G. e Korkas, E. (2007), Rapid micropropagaton of grapevine cv. Agiorgitiko through lateral bud development. e-Journal of Science and Technology, 2, 31-38.

Beardsell, D. V.; Nichols, D. G.; Jones, D. L. (1979), Physical properfies of nursery pottingmixtures. Scientia Horticulturae, 11, 1-8.

Biasi, L. A.; Passos, I. R. S.; Pommer, C. V. (1998), Micropropagação do porta-enxerto de videira 'Jales'. Pesquisa Agropecuária Brasileira, 33, 1587-1594.

Borghezan, M.; Moraes, L. K. A.; Moreira, F. M.; Silva, A. L. (2003), Propagação in vitro e avaliação de parâmetros morfofisiológicos de porta-enxertos de videira. Pesquisa Agropecuária Brasileira, 38, 783-789.
Carvalho, D. C.; Lopes Da Silva, A. L.; Tanno, G. Nakao; Purcino, M.; Biasi, L. A. (2011), Organogênese a partir de segmentos foliares e internodais de videira cv. Merlot. Ciência $e$ Agrotecnologia, 35, 108-114.

Costa, C. A.; Ramos, S. J.; Sampaio, R. A.; Guilherme, D. O.; Fernandes, L. A. (2007), Fibra de coco e resíduo de algodão para substrato de mudas de tomateiro. Horticultura Brasileira, 25, 387-391.

Cruz, C. D. Programa Genes: versão Windows; aplicativo computacional em genética e estatística. Viçosa, MG: UFV, Imprensa Universitária, 2001, 648p.

Cutanda, M. C.; Bouquet, A.; Chatelet, P.; Lopez, G.; Botella, O.; Montero, F. J.; Orregrossa. L. (2008), Somatic embryogenesis and plant regeneration of Vitis vinifera cultivars 'Macabeo' and 'Tempranillo'. Vitis, 47, 159-162.

Franco, D.; Cavalcante, I. H. L.; Oliveira, I. V. M.; Martins, A. B. G. (2007), Avaliação de substratos no desenvolvimento inicial de seis porta-enxertos de citros. Laranja, 28, 61-70.

Fretz, T. A; Read, P. E.; Peele, M. C. Plant propagation lab. Manual. Minneapolis: Burgess Publishiny Company. 1979. 317p.

Hoffmann, A.; Pasqual, M.; Chalfun, N. N. J.; Vieira, S. S. N. (2001), Substratos na indução e desenvolvimento in vitro de raízes em dois portaenxertos de macieira. Pesquisa Agropecuária Brasileira, 36, 1371-1379.

Kämpf, A. N. Produção comercial de mudas ornamentais. Guaíba: Agropecuária, 254p, 2000.

Lopes da Silva, A. L.; Franco, E. T. H.; Walter, J. M.; Bisognin, D. A.; Calgaroto, N. S. (2006), Aclimatização de clones de Dyckia Maritima em diferentes substratos - Bromeliaceae. Revista Brasileira de Agrociência, 12, 495-498.

Lopes da Silva, A. L.; Franco, E. T. H.; Horbach, M. A.; Bisognin, D. A.; Quoirin, M. (2007), Aclimatização de Dyckia maritima Baker em hidroponia (Bromeliaceae). Caderno de Pesquisa Série Biologia, 19, 16-23. 
Lopes da Silva, A. L.; Oliveira, Y.; Costa, J. L.; Scheidt, G. N.; Carvalho, D. C.; Santos, J. D.; Guerra, E. P. (2011), Pré-aclimatização e aclimatização em cultivo hidropônico de plantas micropropagadas de Eucalyptus saligna $\mathrm{Sm}$. Revista Acadêmica: Ciências Agrárias e Ambientais, 9, 179-184.

Machado, M. P.; Lopes da Silva, A. L.; Biasi, L. A. (2011), Effect of plant growth regulators on in vitro regeneration of Lavandula dentata $\mathrm{L}$. shoot tips. Journal of Biotechnology and Biodiversity, 2, 28-31.

Murashige, T. e Skoog, F. (1962), A revised medium for rapid growth and bio assays with tobacco tissue cultures. Physiologia Plantarum, $15,473-479$.

Rosa, M. F.; Santos, F. J. S.; Montenegro, A. A. T.; Abreu, F. A. P.; Correia, D.; Araújo, F. B. S. 2001. Caracterização do pó da casca de coco verde usado como substrato agrícola. Fortaleza: Embrapa-CNPAT, 6 p. (Comunicado Técnico, 54).
Smiderle, O. S. e Minami, K. (2001), Emergência e vigor de plântulas de goiabeira em diferentes substratos. Revista Científica Rural, 6, 38-45.

Sutter, E. e Langhans, R. W. (1982), Formation of epicuticular wax and its effect on water loss in cabbage plants regenerated from shoot-tip culture. Canadian Journal of Botany, 60, 2896-2902.

Verdonck, O.; Vleeschauwer, D.; Boodt, M. (1981), The influence of the substrate to plant growth. Acta Horticulturae, 126, 251-258.

Villa, F.; Pasqual, M.; Araújo, A. G.; Pio, L. A. S. (2006), Micropropagação da amoreira-preta (Rubus spp.) e efeito de substratos na aclimatização de plântulas. Acta Scientiarum. Agronomy, 28, 47-53.

Zanetti, M.; Fernandes, C.; Cazetta, J. O.; Corá, J. E.; Mattos Jr., D. (2003), Caracterização física de substratos para a produção de mudas e portaenxertos cítricos sob telado. Laranja, 24, 519-530. 